\title{
An in situ postexposure feeding assay with Carcinus maenas for estuarine sediment-overlying water toxicity evaluations
}

\author{
Susana M. Moreira ${ }^{\mathrm{a}, \mathrm{b}}$, Matilde Moreira-Santos ${ }^{\mathrm{c}}$, \\ Lúcia Guilhermino ${ }^{\mathrm{a}, \mathrm{b}}$, Rui Ribeiro ${ }^{\mathrm{c}, *}$ \\ a Instituto de Ciências Biomédicas de Abel Salazar (ICBAS), Departamento de Estudos de Populações, \\ Largo Abel Salazar 2, 4099-003 Porto, Portugal \\ ${ }^{\mathrm{b}}$ Centro Interdisciplinar de Investigação Marinha e Ambiental, Laboratório de Ecotoxicologia, \\ Rua dos Bragas 289, 4050-123 Porto, Portugal \\ c Instituto do Ambiente e Vida, Departamento de Zoologia da Universidade de Coimbra, \\ Largo Marquês de Pombal, 3004-517 Coimbra, Portugal
}

Received 4 November 2004; accepted 13 May 2005

A new sub-lethal toxicity assay is presented for marine invertebrates.

\begin{abstract}
This study developed and evaluated a short-term sublethal in situ toxicity assay for estuarine sediment-overlying waters, with the crab Carcinus maenas (L.) based on postexposure feeding. It consisted of a 48-h in situ exposure period followed by a short postexposure feeding period $(30 \mathrm{~min}$ ). A precise method for quantifying feeding, using the Polychaeta Hediste (Nereis) diversicolor Müller as food source, was first developed. The sensitivity of the postexposure feeding response was verified by comparing it to that of lethality, upon cadmium exposure. The influence of environmental conditions prevailing during exposure (salinity, temperature, substrate, light regime, and food availability) on postexposure feeding was also addressed. The potential of this in situ assay was then investigated by deploying organisms at ten sites, located in reference and contaminated Portuguese estuaries. Organism recovery ranged between $90 \%$ and $100 \%$ and a significant postexposure feeding depression $(16.3-72.7 \%)$ was observed at all contaminated sites relatively to references.
\end{abstract}

(C) 2005 Elsevier Ltd. All rights reserved.

Keywords: In situ assay; Sediment-overlying water toxicity; Postexposure feeding; Estuary; Carcinus maenas

\section{Introduction}

Estuaries, along with their adjacent salt marshes, rank among the most productive ecosystems on earth, being crucial to the life history (e.g. nursery, rearing, feeding, and migration) of many aquatic species (Chapman and Wang, 2001). Controversially, these ecosystems are

\footnotetext{
* Corresponding author: Tel.: +351 239 822241; fax: +351 239 826798.

E-mail address: rui.ribeiro@zoo.uc.pt (R. Ribeiro).
}

being rapidly degraded by contaminant inputs from both point and nonpoint sources, upstream and within the estuary catchments, ranking them also as the most anthropogenic ecosystems on earth (Lytle and Lytle, 2001). Therefore, there is a clear requirement for the development of ecotoxicological tools for ecological risk assessments in estuaries, particularly those concerning sediment contamination (Chapman and Wang, 2001).

In opposition to standardized laboratory toxicity testing, in situ assays incorporate much of the natural fluctuating environmental conditions, allowing a more realistic exposure and, as a result, generate more 
ecologically relevant information for the area under study (Castro et al., 2003; Chappie and Burton, 2000). This is particularly relevant for estuarine systems because estuaries provide an interface between fresh and salt waters and are tidally influenced environments, presenting strong spatial and temporal gradients in many physical and chemical parameters and biological processes (Chapman and Wang, 2001). Despite the fact that the development of methodologies to assess toxicity in situ has greatly increased in the past years, few of those were applied in estuaries (Moreira et al., in press; Moreira dos Santos et al., 2002; Ringwood and Keppler, 2002).

Feeding impairment, either during or after contamination exposure, has been successfully employed as an in situ assay endpoint for various groups of aquatic organisms (Castro et al., 2004; Maltby et al., 2002; McWilliam and Baird, 2002a; Smolders et al., 2004). A recent study by Moreira et al. (in press) investigated the use of postexposure feeding as a sublethal endpoint for use in in situ estuarine sediment toxicity assessments with the Polychaeta Hediste (Nereis) diversicolor Müller. As discussed by McWilliam and Baird (2002a,b), the use of a postexposure period to quantify feeding circumvents procedural problems in experimental designs associated with the quantification of feeding during in situ exposures while keeping ecological relevance. The latter authors and several other studies showed that feeding depression is a sensitive sublethal endpoint, capable of responding to toxicants in a short period of time, both in the laboratory and in situ (Barata and Baird, 2000; Castro et al., 2004; McLoughlin et al., 2000; Moreira et al., in press). Also, the fact that impairment of feeding at the individual level has often been demonstrated to have direct effects on population parameters (e.g. growth, reproduction and eventually survival), allows the mechanistic recognition of feeding depression as an ecologically relevant response (Maltby et al., 2001).

The main aim of this study was to develop a shortterm sublethal in situ assay for estuarine sedimentoverlying water toxicity assessments, with the crab Carcinus maenas (L.), based on postexposure feeding. To attain this objective, four experimental phases were delineated to: (1) develop a simple methodology to accurately quantify $C$. maenas postexposure feeding rates in a short period, in order to prevent an eventual physiological recovery after toxicant exposure; (2) investigate the sensitivity of the postexposure feeding response, by exposing organisms to sublethal and lethal concentrations of cadmium; (3) assess the influence of a number of environmental exposure conditions (salinity, temperature, substrate, light regime, and food availability) on postexposure feeding, given that these variables have been associated with background variability in feeding rates (Maltby et al., 2002; Moreira et al., in press; Soares et al., in press); and (4) evaluate the effectiveness of the proposed in situ assay for toxicity assessments in estuaries. This latter phase was carried out by deploying organisms at two reference and five contaminated estuaries along the Portuguese coast.

Carcinus maenas, commonly referred to as the European green crab, is a portunid crab native to Europe and probably also to Northwest Africa (Cohen et al., 1995). This extremely eurythermal and euryhaline species has received much attention because of its success as a global invader, with established reproductive populations noticed on both the east and west coast of North America, South Africa and Australia (Cohen et al., 1995). Carcinus maenas is an opportunistic feeder, consuming a large variety of prey items, including organisms from 14 animal phyla (mainly Crustacea, Mollusca and Annelida), and five plant and protist phyla (Cohen et al., 1995). Its voracious predatory behavior is thought to be an important feature in structuring marine and estuarine benthic communities (Raffaelli et al., 1989). The ecological important role of C. maenas and its widespread distribution and abundance in coastal and estuarine waters constitute major reasons for its frequent use in laboratory toxicity assessments (e.g. Watson et al., 2004). Yet, a search in specialized literature revealed that this epibenthic crustacean has hardly ever been used for estuarine in situ assays (Astley et al., 1999).

\section{Materials and methods}

\subsection{Collection and maintenance of assay organisms}

Shore crabs were handpicked at low tide at the Mira estuary (see Section 2.6) and transported to the laboratory in thermally insulated boxes with locally collected water. To avoid behavioral and physiological variability associated with $C$. maenas color phases (Reid et al., 1997) and body size (Elner, 1980), only green color-form individuals of uniform size were selected for this study. Mean ( \pm standard deviation $[\mathrm{SD}] ; n=30$ ) carapace width (maximum distance between the two prominent lateral spines) and dry weight of selected organisms were $2.18( \pm 0.08) \mathrm{cm}$ and 797.69 $( \pm 28.60) \mathrm{mg}$, respectively. Organisms presenting signs of being infected by the parasitic barnacle Sacculina carcini Thompson were discarded. In the laboratory, females and males were individually maintained in plastic containers with seawater of $20 \mathrm{~g} / \mathrm{L}$ salinity, and kept in a temperature-controlled room at $20 \pm 1{ }^{\circ} \mathrm{C}$, under a 16:8-h light/dark cycle. Culture water was obtained by diluting filtered $(1.2 \mu \mathrm{m})$ natural seawater of $35 \mathrm{~g} / \mathrm{L}$ salinity with dechlorinated tap water. Crabs were daily fed ad libitum with a commercial flake food (TetraMenu, Tetrawerke, Melle, Germany). 


\subsection{Feeding quantification}

To develop the methodology to quantify postexposure feeding rates of $C$. maenas, four types of food were preliminary tested, a commercial fish flake food (TetraMenu), newly hatched (48-h) Artemia fransciscana Kellog nauplii, dried Gammarus sp. (Astra, Melle, Germany), and dried pieces of the Polychaeta $H$. diversicolor. The pieces of the polychaetes were found to be the most suitable food for the feeding rate quantification of $C$. maenas, both in terms of consumption rate and consistency of results (data not shown), and were thus selected to be used in the in situ assay here proposed. To prepare this food item, juvenile individuals of $H$. diversicolor were handpicked at low tide from the intertidal sediments of the Mira estuary. Following their capture, organisms were air dried and uniformly sized pieces of about two body segments were cut with scissors (mean \pm SD dry weight was $94.47 \pm 4.82 \mathrm{mg}, n=6$ ). For the definitive feeding trial, five male and five female crabs (10 replicates) were selected at random from the laboratory cultures and individually transferred to crystallizing dishes $(6 \mathrm{~cm}$ height, $11 \mathrm{~cm}$ i.d.) containing $150 \mathrm{~mL}$ of ASPM water of $20 \mathrm{~g} / \mathrm{L}$ salinity (ASPM medium). To prepare the ASPM medium, ASPM (J. McLachlan's modification of the Artificial Seawater with L. Provasoli's metal mix PI) reconstituted seawater of $35 \mathrm{~g} / \mathrm{L}$ salinity (Guillard, 1983) was diluted with ASTM reconstituted hard water (ASTM, 2002). Fifty dried pieces of about two segments of $H$. diversicolor were added to the medium and organisms were allowed to feed for $30 \mathrm{~min}$, at $20 \pm 1{ }^{\circ} \mathrm{C}$, in the dark. At the end of this feeding period, individuals were carefully removed from the vials and all remaining pieces of $H$. diversicolor were counted. Individual feeding rates were determined as pieces $/ \mathrm{min}$. Under the established controlled conditions, a quantity of 50 pieces of $H$. diversicolor was sufficient to prevent the complete depletion of the food during the 30-min feeding period. To optimize the feeding rate of $C$. maenas, the influence of gender and light conditions during the 30 -min feeding period was investigated separately, following the same controlled conditions just described, except for the experimental variable. Two light regimes were investigated using only male individuals: feeding in darkness and under a continuous cool-white fluorescent light $\left(100 \mu \mathrm{E} / \mathrm{m}^{2} / \mathrm{s}\right)$. Prior to all feeding trials, organisms were deprived of food for $24 \mathrm{~h}$ in order to standardize nutritional storage levels across individuals.

\subsection{Endpoint sensitivity}

The sensitivity of the postexposure feeding response was investigated by exposing organisms to sublethal and lethal concentrations of cadmium. A stock solution of cadmium was prepared in nanopure water, using cadmium chloride monohydrate (1.02011, Merck, Darmstadt, Germany). Test solutions were made from the stock solution by adding the appropriate subsamples to ASPM medium. For the lethality tests, seven nominal concentrations of cadmium were tested using a dilution factor of $0.6(0,3.00,5.00,8.33,13.89,23.12$, and $38.58 \mathrm{mg} / \mathrm{L}$ ). Mortality was daily registered and the median lethal concentration $\left(\mathrm{LC}_{50}\right)$ was determined after 48- and 96-h exposure periods. To estimate the median inhibitory concentration $\left(\mathrm{IC}_{50}\right)$ of cadmium for postexposure feeding, organisms were exposed during $48 \mathrm{~h}$ to six nominal concentrations of cadmium $(0,1.08$, $1.80,3.00,5.00$, and $8.33 \mathrm{mg} / \mathrm{L}$ ), followed by a $30-\mathrm{min}$ feeding period, under the conditions described in the previous section. In both toxicity tests, two sets of five replicates, with one organism each, were set up per treatment, one for females and another for males. The tests were carried out in $500-\mathrm{mL}$ transparent polyethylene terephthalate vials $(10 \mathrm{~cm}$ height, $8 \mathrm{~cm}$ i.d.) containing $150 \mathrm{~mL}$ of the test solution, at $20 \pm 1{ }^{\circ} \mathrm{C}$, under a 16:8-h light/dark cycle. Test solutions were changed every $48 \mathrm{~h}$. No food was added during the tests.

For cadmium analysis, additional triplicate test solutions of each concentration were prepared at the beginning of each experiment. Test solutions of the highest cadmium concentration $(38.58 \mathrm{mg} / \mathrm{L})$ were also analyzed in triplicate after $48 \mathrm{~h}$, to observe whether concentrations were maintained during the experiment. Cadmium concentrations were analyzed by electrothermal atomic absorption spectrophotometry (Varian, SpectrAA 220 FSM, Palo Alto, USA). Minimum detection limit for cadmium was $0.09 \mathrm{mg} / \mathrm{L}$.

\subsection{Influence of exposure conditions on postexposure feeding}

The influence of the following environmental conditions prevailing during a 48 - $\mathrm{h}$ exposure period on the postexposure feeding rate of $C$. maenas was investigated separately: salinity, temperature, substrate, light regime, and food availability. Unless otherwise stated, organisms were exposed individually, during $48 \mathrm{~h}$, in $500-\mathrm{mL}$ transparent polyethylene terephthalate vials containing $150 \mathrm{~mL}$ of ASPM medium, at $20 \pm 1{ }^{\circ} \mathrm{C}$, under a $16: 8$-h light/dark photoperiod, without food addition. Two sets of five replicates, one for females and another for males, were used in all treatments. After exposure, organisms were carefully retrieved from vials and postexposure feeding determinations were immediately carried out as above described (see Section 2.2).

To determine whether postexposure feeding is affected by salinity, seven treatments, from 5 to $35 \mathrm{~g} / \mathrm{L}$, were used. Waters with a salinity ranging from 5 to $30 \mathrm{~g} / \mathrm{L}$ were obtained by diluting the $35-\mathrm{g} / \mathrm{L}$ salinity ASPM water (Guillard, 1983) with ASTM hard water (ASTM, 2002). To determine whether postexposure feeding is 
affected by temperature, five treatments were tested in controlled temperature rooms at 10, 15, 20, 25, and $30 \pm 1{ }^{\circ} \mathrm{C}$. Although it is outside the water temperature range of Portuguese estuaries, the temperature of $30^{\circ} \mathrm{C}$ was also included in this experiment to assess the potential of the proposed in situ assay for warmer regions. At the end of the 48-h exposure period, and prior to the postexposure feeding determinations, all organisms were subjected to a 4 -h thermal acclimation period at $20 \pm 1{ }^{\circ} \mathrm{C}$, to simulate the transport of organisms from the field to the laboratory. To determine the influence of substrate on postexposure feeding rates, five sediments differing in particle size composition, and a water only treatment (ASPM medium) were evaluated. The five sediments were: very coarse $(>1000 \mu \mathrm{m}$ particles), coarse (500-1000 $\mu \mathrm{m}$ particles), medium size $(250-500 \mu \mathrm{m}$ particles), fine and very fine sand (63-250 $\mu \mathrm{m}$ particles), and silt/clay ( $<63 \mu \mathrm{m}$ particles). To prepare the experimental sediments, different sediments were collected at the Mira estuary, at low tide, sealed in black airtight plastic buckets and stored at $4{ }^{\circ} \mathrm{C}$ until use. Samples were first homogenized by removing visible indigenous animals and large debris with a forceps. A standard sieving technique consisting of a set of four sieves (Retsch, Haan, Germany) with mesh sizes ranging from 63 to $1000 \mu \mathrm{m}$ was used to separate the sediment fractions (Buchanan and Kain, 1971). A layer of sediment of approximately 3-cm high was introduced into the $500-\mathrm{mL}$ vials, which were then carefully filled with the $150 \mathrm{~mL}$ of ASPM medium. Organisms were only added after $24 \mathrm{~h}$, to allow sediment setting. The effect of light regime was determined by exposing organisms under a 16:8-h light/dark cycle and under dark conditions. To investigate the influence of food availability, organisms were exposed under two treatments: no food supply and an ad libitum diet composed of commercial flake food (TetraMenu), supplied every $12 \mathrm{~h}$. To further investigate the influence of food availability prior to the feeding quantification period, another experiment was carried out using exposure durations of 48, 96 and $192 \mathrm{~h}$, without adding food.

\subsection{In situ assay}

To evaluate the suitability of the here proposed in situ assay chambers and procedures, an assay was carried out at reference and contaminated Portuguese estuaries. Assay chambers (Fig. 1) were an adaptation of those previously developed for the short-term field exposure of Chironomus riparius Meigen larvae (Soares et al., in press). Each chamber consisted of a $20-\mathrm{cm}$ long transparent acrylic tube $(0.5 \mathrm{~cm}$ thick and $5 \mathrm{~cm}$ i.d.), with two rectangular windows $(4 \times 10 \mathrm{~cm})$ on opposite sides, covered with a $200-\mu \mathrm{m}$ nylon mesh fixed with white-thermal non-toxic glue (TN122/WS, Elis Taiwan, Taiwan). The bottom end edge was slimmed (for $1 \mathrm{~cm}$

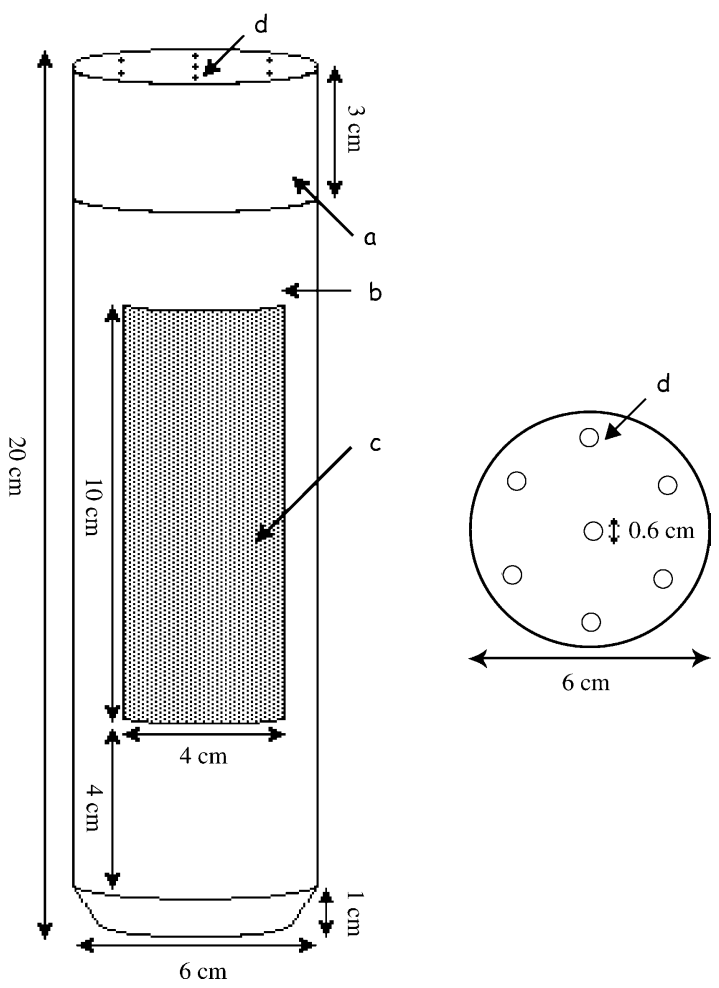

Fig. 1. Assay chamber design for the 48 -h in situ assay with Carcinus maenas: side and top view. (a) Three-centimeter long and 6-cm i.d. transparent polyethylene terephthalate cap; (b) $20-\mathrm{cm}$ long and $4-\mathrm{cm}$ i.d. acrylic tube; (c) $4 \times 10-\mathrm{cm} 200-\mu \mathrm{m}$ nylon mesh lateral window; (d) $0.6-\mathrm{cm}$ i.d. opening on the chamber cap.

at $\sim 30^{\circ}$ ) to facilitate penetration into the sediment. The top end was covered with a fitting transparent polyethylene terephthalate cap ( $\sim 3 \mathrm{~cm}$ height), uniformly perforated with seven circular openings $(\sim 0.6 \mathrm{~cm})$. This cover guaranteed a proper overlying water flow/renewal and aeration, avoiding also both the escape of the organisms and their possible predation by indigenous fish or birds.

Two sets of five replicate chambers, one with females and another with males, with one organism per chamber, were deployed at each site. All deployments were carried out at the lowest level of low tide, to avoid air exposure of organisms during the assay. Chambers were carefully pushed into the sediment to a depth of about $14 \mathrm{~cm}$, so that the lateral windows allowed both the flow of the overlying water at the water-column level and porewater at the sediment level. No food was added during the assay. After a 48-h exposure period, chambers were retrieved from the sediment (also at low tide). Each chamber was placed inside fitting black plastic bags and transported to the laboratory inside thermally insulated boxes. A 4-h period since the retrieval of the chambers until postexposure feeding quantifications was fixed, with the aim of providing similar conditions among sites. At the end of this period, individuals were gently retrieved from the chambers for 
immediate determination of postexposure feeding rates, according to the conditions previously described.

The range of water-column salinity and temperature values (Wissenschaftlich Technische Werkstätten, LF 330, WTW, Weilheim, Germany) was recorded by measuring these parameters at the lowest and highest level of low and high tide, respectively, during the 48-h exposure period. At the end of the assay, composite sediment samples were collected from each chamber, sealed in black airtight plastic containers, and stored at $4{ }^{\circ} \mathrm{C}$ until processed for sediment characterization. Organic matter content (percent volatile solids) was determined by quantifying the loss of weight after ignition at $550{ }^{\circ} \mathrm{C}$ for $4 \mathrm{~h}$, and was expressed as the percentage of the oven-dry weight of the sediment (Buchanan and Kain, 1971). The sediment particle size distribution was analyzed by sieving $25 \mathrm{~g}$ of sediment (previously dried at $105{ }^{\circ} \mathrm{C}$ for $24 \mathrm{~h}$ ) into six fractions, ranging from 63 to $1000 \mu \mathrm{m}$. The sediment remaining on each sieve was weighted to the nearest microgram, expressed as a percentage of the total final weight, and classified according to the Wentworth scale (Buchanan and Kain, 1971).

\subsection{Study sites}

The in situ assay was carried out in seven estuaries along the Portuguese coast (Fig. 2). The selection of the estuaries and their categorization into reference (site R1, at the Minho estuary and sites R2a to R2d, at the Mira estuary) and contaminated (sites S1 to S5 located at Lima, Cávado, Ave, Douro, and Mondego estuaries, respectively) was based on analytical data available in the literature (Azevedo et al., 2000; Ferreira et al., 2003; Gonçalves et al., 1994; Guerreiro and Pereira, 2002; Lacorte et al., 2001; Mucha et al., 2003; Soares et al., 1999; Tauler et al., 2004). Most of these data were obtained during an extensive monitoring program (from April 1999 to May 2000, ordered by the Portuguese Environmental Ministry) to determine contaminant levels in surface waters of the most important Portuguese river basins, concerning the survey of priority dangerous substances related to the implementation of the EU directive 76/464/ECC (now integrated in the Water Framework Directive 2000/60/EC) (Commission of the European Communities, 1976).

Briefly, the Lima River estuary (site S1, $41^{\circ} 41^{\prime} 53^{\prime \prime} \mathrm{N}$, $\left.8^{\circ} 48^{\prime} 15^{\prime \prime} \mathrm{W}\right)$ supports a pulp and paper mill, and is the location of an industrial harbor and a shipyard (Guerreiro and Pereira, 2002). The Cávado River runs through an industrialized area, receiving into its estuary (site S2, $41^{\circ} 32^{\prime} 16^{\prime \prime} \mathrm{N}, 8^{\circ} 47^{\prime} 8^{\prime \prime} \mathrm{W}$ ) untreated effluents from mining activities, textile and ceramic manufacturers, metal plating industries, paperboard mills, and slaughterhouses (Gonçalves et al., 1994; Guerreiro and Pereira, 2002). Major sources of contamination in the
Ave River estuary (site S3, $41^{\circ} 20^{\prime} 49^{\prime \prime} \mathrm{N}, 8^{\circ} 44^{\prime} 34^{\prime \prime}$ W) are related to the textile sector, followed by leather tanning, rubber manufacture and plastic production (Guerreiro and Pereira, 2002; Soares et al., 1999). The Douro River forms a mesotidal estuary (site S4, $41^{\circ} 8^{\prime} 35^{\prime \prime} \mathrm{N}, 8^{\circ} 38^{\prime} 53^{\prime \prime} \mathrm{W}$ ) in the last $22 \mathrm{~km}$, receiving domestic sewage of over one million inhabitants, as well as industrial effluents (e.g. food processing and metal plating industry), mostly without treatment (Guerreiro and Pereira, 2002; Mucha et al., 2003). Major sources of contamination in the Mondego River estuary (site S5, $40^{\circ} 8^{\prime} 10^{\prime \prime} \mathrm{N}, 8^{\circ} 50^{\prime} 51^{\prime \prime} \mathrm{W}$ ) include a mercantile harbor, urban and industrial wastewaters, and discharges from aquaculture farms and intensive agriculture areas, responsible for an ongoing eutrophication process (Ferreira et al., 2003; Guerreiro and Pereira, 2003). The Minho River estuary (site R1, $41^{\circ} 53^{\prime} 27^{\prime \prime} \mathrm{N}, 8^{\circ} 49^{\prime} 29^{\prime \prime} \mathrm{W}$ ) is about $35 \mathrm{~km}$ long and comprises an area of $2 \mathrm{~km}^{2}$ of salt marshes (Ferreira et al., 2003). The Mira estuary (sites $\mathrm{R} 2 \mathrm{a}$ to $\mathrm{R} 2 \mathrm{~d}$ ) is a narrow entrenched pristine estuary about $30 \mathrm{~km}$ long, being part of it bordered by salt marshes that cover an area of about $2.9 \mathrm{~km}^{2}$ (Ferreira et al., 2003). Four sites were chosen along an increasing salinity gradient (R2a, 37 $36^{\prime} 48^{\prime \prime} \mathrm{N}, 8^{\circ} 39^{\prime} 07^{\prime \prime} \mathrm{W}$; R2b, $37^{\circ} 38^{\prime} 59^{\prime \prime} \mathrm{N}, 8^{\circ} 42^{\prime} 32^{\prime \prime} \mathrm{W} ; \mathrm{R} 3 \mathrm{c}, 37^{\circ} 39^{\prime} 97^{\prime \prime} \mathrm{N}$,

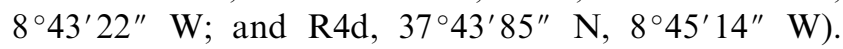
The five reference sites were selected to enable the determination of postexposure feeding rates over a range of salinity, temperature and sediment characteristics.

\subsection{Data analysis}

The influence of gender and light conditions during the 30-min feeding period was tested through independent samples $t$-tests (Zar, 1996). Since no significant differences were found between female and male feeding rates, the two sets of five replicates of each treatment were pooled in all subsequent analysis. The $\mathrm{LC}_{50}$ and the $\mathrm{IC}_{50}$ of cadmium for postexposure feeding and the corresponding $95 \%$ confidence limits were calculated by probit analysis using PriProbit 1.63 software (Sakuma, 1998) (http://bru.gmprc.ksu.edu/proj/priprobit/download. asp). The influence of exposure conditions on the postexposure feeding rate was tested through independent samples $t$-tests or one-way ANOVAs, followed (if applicable) by Tukey honestly significant difference (HSD) multiple-comparison tests (Zar, 1996). Since temperature and salinity were shown to significantly influence postexposure feeding rates of $C$. maenas, nonlinear regression models were fitted to feeding rates as a function of salinity $(5-35 \mathrm{~g} / \mathrm{L})$ and temperature $\left(10-25^{\circ} \mathrm{C}\right)$, to allow adjusting feeding rate values from the in situ assay to a constant salinity and temperature. For the in situ assay, the mean percentage of C. maenas recovered from chambers, either dead or alive, was calculated after the 48 -h exposure period. The mean 


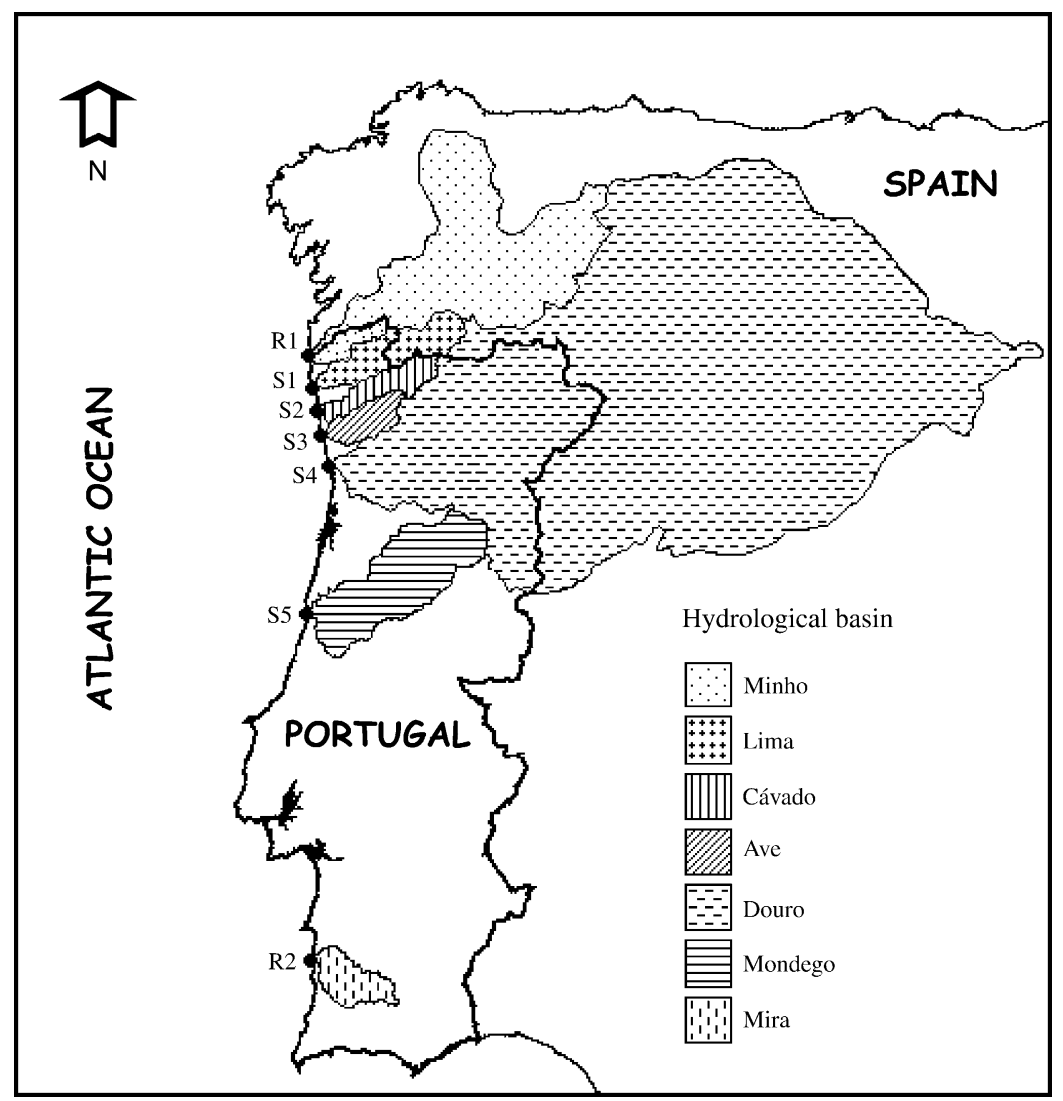

Fig. 2. Map showing the hydrological basin of the Minho, Lima, Cávado, Ave, Douro, Mondego, and Mira Rivers and the location of the estuary sites where the in situ assay with Carcinus maenas was performed. Deployments were carried out at two reference (R1 and R2) and five impacted (S1 to S5) estuaries.

percentage of survival was also calculated based on the number of recovered individuals. Postexposure feeding rates were calculated as a proportion of the postexposure feeding rates predicted by the salinity and temperature models, for the median water column salinity and temperatures registered at each site, respectively. Then, relative postexposure feeding rates were adjusted to a salinity of $20 \mathrm{~g} / \mathrm{L}$ and a temperature of $20^{\circ} \mathrm{C}$. Adjusted postexposure feeding rates of organisms deployed at all sites were compared through a one-way ANOVA, followed by a Tukey HSD test (Zar, 1996). Feeding rates at each impacted site were then compared with pooled references through one-tailed $t$-tests, since no significant differences were found across reference sites (Zar, 1996).

\section{Results}

\subsection{Feeding quantification}

Mean $( \pm \mathrm{SD})$ feeding rates of females and males were similar $\left(t_{18}=0.16, p>0.05\right) ; 0.833( \pm 0.152)$ and 0.790 $( \pm 0.135)$ pieces $/ \mathrm{min}$, respectively, with the coefficient of variation $(\mathrm{CV}) \leq 18 \%$. The feeding rate of $C$. maenas was not significantly influenced by different light conditions $\left(t_{18}=0.12, p>0.05\right)$. Mean $( \pm \mathrm{SD})$ feeding rates of organisms feeding in darkness and under a continuous cool-white fluorescent were $0.933( \pm 0.137)$ and $0.893( \pm 0.134)$ pieces $/ \mathrm{min}$, respectively. Yet, the $\mathrm{CV}$ of feeding in darkness $(17 \%)$ was below that of feeding under continuous light $(25 \%)$.

\subsection{Endpoint sensitivity}

Nominal concentrations of cadmium were used for all calculations because they differed by less than $7 \%$ from actual concentrations. The 48- and 96-h $\mathrm{LC}_{50}$ (95\% confidence limits) of cadmium were 27.92 (21.19$37.58)$ and $13.97(9.73-18.51) \mathrm{mg} / \mathrm{L}$, respectively. The 48 -h $\mathrm{IC}_{50}$ for postexposure feeding $(95 \%$ confidence limits) was $4.33(3.78-5.06) \mathrm{mg} / \mathrm{L}$ of cadmium. No control mortality was observed in either of the toxicity tests and no mortality was registered during the sublethal test.

\subsection{Influence of exposure conditions on postexposure feeding}

The influence of salinity and temperature on the postexposure feeding rate of $C$. maenas is shown in 


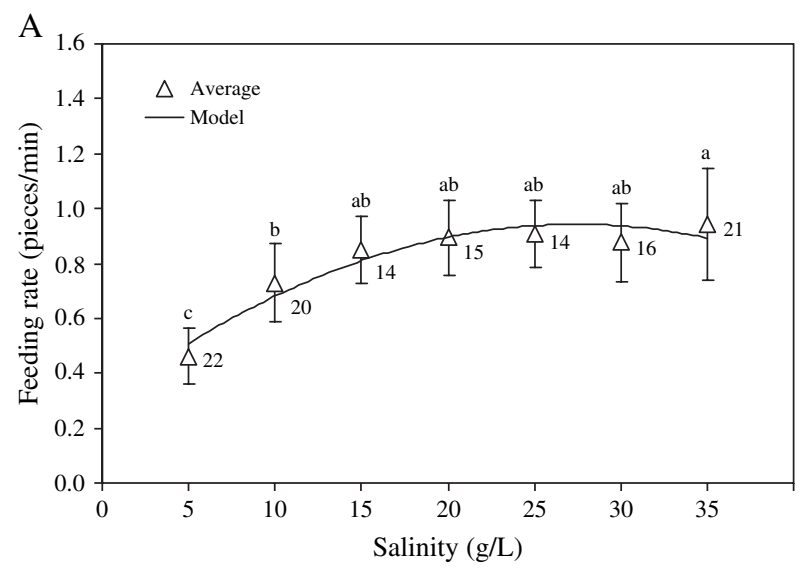

B

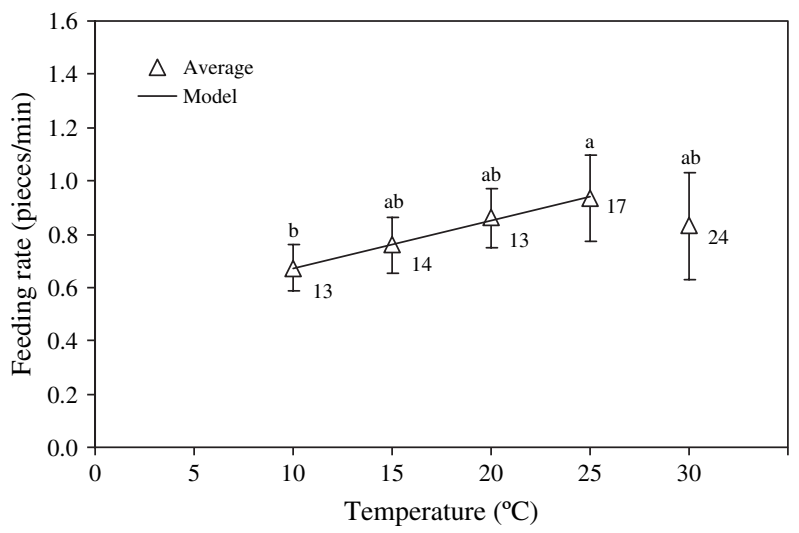

Fig. 3. Mean $(n=10)$ postexposure feeding rates of Carcinus maenas after a 48-h laboratory exposure to different salinities (A) and temperatures (B). Error bars indicate \pm 1 standard deviation; numbers alongside stand for coefficient of variation (\%); common letters above error bars identify homogeneous groups by Tukey honestly significant difference multiple-comparison test $(p \leq 0.05)$. The lines of the respective nonlinear regression models are presented.

Fig. 3. Salinity significantly influenced the postexposure feeding of $C$. maenas $\left(F_{(6,61)}=11.67, p<10^{-3}\right)$. Feeding was significantly lower at $5 \mathrm{~g} / \mathrm{L}$ compared to all other salinities, and significantly higher at 35 than at $10 \mathrm{~g} / \mathrm{L}$ salinity. Mortality was registered only at $5 \mathrm{~g} / \mathrm{L}(20 \%)$. The relationship between postexposure feeding $(y)$ and exposure salinity $(x)$, within the studied range, was expressed by the nonlinear regression model ( \pm standard error [SE]): $y=-0.000863( \pm 0.000251) x^{2}+$ $0.0473( \pm 0.0103) x+0.294( \pm 0.090) \quad\left(r^{2}=92.1 \%, p<0.005\right.$, $n=7)$. Postexposure feeding was also significantly influenced by exposure at different temperatures $\left(F_{(4,45)}=5.2, p<0.005\right)$. Feeding was significantly higher at 25 than at $10{ }^{\circ} \mathrm{C}$. The relationship between postexposure feeding $(y)$ and exposure temperature $(x)$, within the range of 10 to $25^{\circ} \mathrm{C}$, was expressed by the nonlinear regression model $( \pm \mathrm{SE})$ : $y=-0.0001$ $( \pm 0.000164) x^{2}+0.0213( \pm 0.00579) x+0.469( \pm 0.0471)$ $\left(r^{2}=99.8 \%, p<0.05, n=4\right)$. Postexposure feeding was not significantly influenced by exposure to different substrate types $\left(F_{(5,54)}=1.37, p>0.05\right)$. Mean $( \pm \mathrm{SD})$ feeding rates ranged from $0.763( \pm 0.159)$ to 0.900 $( \pm 0.086) \mathrm{pieces} / \mathrm{min}$, for organisms exposed in medium sand $(250-500 \mu \mathrm{m}$ particles $)$ and silt/clay $(<63 \mu \mathrm{m}$ particles), respectively, with $\mathrm{CVs}$ in all treatments $\leq 15 \%$. Mean $( \pm \mathrm{SD})$ feeding rates of organisms exposed under a 16:8-h light/dark cycle and dark conditions were similar $\left(t_{18}=0.66, p>0.05\right) ; 0.893( \pm 0.134)$ and $0.933( \pm 0.137)$ pieces $/ \mathrm{min}$, respectively, with $\mathrm{CVs} \leq 15 \%$. Organisms exposed for $48 \mathrm{~h}$ with an ad libitum diet and without food had similar (mean \pm SD) feeding rates $\left(t_{18}=0.7, \quad p>0.05\right) ; \quad 0.840 \pm 0.201 \quad(\mathrm{CV}=24 \%) \quad$ and $0.893 \pm 0.134 \mathrm{pieces} / \mathrm{min}(\mathrm{CV}=15 \%)$, respectively. The extension of the exposure duration without food from 48 to 96 and $192 \mathrm{~h}$ did not influence the mean $( \pm \mathrm{SD})$ feeding rate of $C$. maenas $\left(F_{(2,27)}=1.45, p>0.05\right)$, which ranged from $0.827( \pm 0.149)$ to $0.957( \pm 0.251)$ pieces/min, with $\mathrm{CVs} \leq 26 \%$.

\subsection{In situ assay}

The range of water-column salinity and temperature values registered at each study site at the lowest level of low tide and at the highest level of high tide during the in situ assay are shown in Table 1. Except at sites R2d and S5, high salinity fluctuations were observed in overlying waters at all sites. Small water-column temperature fluctuations $\left(\leq 3.2{ }^{\circ} \mathrm{C}\right)$ were observed at all sites. Results of the sediment particle size distribution and organic matter content at each site are summarized in Table 2. Sediments from site R1 were mainly $(70.7 \%)$ composed of fine $(125-250 \mu \mathrm{m})$ and very fine $(63-125 \mu \mathrm{m})$ sand, whereas those from site R2 of silt/clay $(<63 \mu \mathrm{m})(89.7 \%$ at R2a to $49.8 \%$ at R2d). Sediments from contaminated sites were all, except those of site S3 (67.6\% of particles $>1000 \mu \mathrm{m})$, mainly composed of particles smaller than $500 \mu \mathrm{m}$, with those of sites S4 and S5 having the highest portion of silt and clay. Sediments from sites R2a, R2b, $\mathrm{R} 2 \mathrm{~d}$, and S5 had the highest organic matter content.

Table 1

Range of water-column salinities and temperatures registered at each study site, at the lowest level of low tide and at the highest level of high tide, during the 48-h in situ assay with Carcinus maenas

\begin{tabular}{lcl}
\hline Site & Salinity $(\mathrm{g} / \mathrm{L})$ & Temperature $\left({ }^{\circ} \mathrm{C}\right)$ \\
\hline R1 & $7.4-19.1$ & $13.6-14.2$ \\
R2a & $26.2-18.6$ & $21.0-22.3$ \\
R2b & $21.6-28.8$ & $21.2-22.8$ \\
R2c & $24.9-31.8$ & $21.2-21.8$ \\
R2d & $33.5-35.7$ & $17.6-20.8$ \\
S1 & $14.1-26.1$ & $16.3-18.6$ \\
S2 & $8.6-16.9$ & $16.4-16.7$ \\
S3 & $7.8-19.4$ & $15.6-15.9$ \\
S4 & $5.8-14.1$ & $15.6-16.1$ \\
S5 & $32.0-35.0$ & $14.7-16.4$ \\
\hline
\end{tabular}


Table 2

Percentage results of particle size distribution and organic matter (volatile solids) content for sediments collected at each study site at the end of the 48-h in situ assay with Carcinus maenas

\begin{tabular}{|c|c|c|c|c|c|c|c|c|c|c|}
\hline \multirow[t]{2}{*}{ Particle size $(\mu \mathrm{m})$} & \multicolumn{10}{|l|}{ Site } \\
\hline & $\mathrm{R} 1$ & R2a & $\mathrm{R} 2 \mathrm{~b}$ & $\mathrm{R} 2 \mathrm{c}$ & $\mathrm{R} 2 \mathrm{~d}$ & S1 & S2 & S3 & S4 & S5 \\
\hline$>1000$ & 0.26 & 0.00 & 0.00 & 0.00 & 0.52 & 24.54 & 5.89 & 67.63 & 7.92 & 1.83 \\
\hline $500-1000$ & 0.55 & 0.00 & 0.20 & 0.21 & 0.24 & 11.24 & 5.48 & 9.58 & 11.09 & 6.09 \\
\hline $250-500$ & 5.21 & 0.00 & 0.40 & 1.03 & 1.07 & 18.60 & 18.75 & 7.91 & 12.96 & 19.79 \\
\hline $125-250$ & 24.06 & 1.40 & 3.21 & 9.78 & 15.84 & 14.86 & 25.60 & 6.71 & 9.06 & 16.57 \\
\hline $63-125$ & 46.66 & 8.90 & 20.64 & 22.00 & 32.51 & 12.28 & 23.48 & 5.04 & 19.66 & 18.53 \\
\hline$<63$ & 23.26 & 89.70 & 75.55 & 66.98 & 49.82 & 18.48 & 20.79 & 3.14 & 39.32 & 37.19 \\
\hline Organic matter & 4.2 & 7.5 & 6.3 & 5.4 & 8.6 & 5.2 & 3.9 & 3.6 & 5.2 & 6.9 \\
\hline
\end{tabular}

Recovery, survival and adjusted postexposure feeding rates (to a salinity of $20 \mathrm{~g} / \mathrm{L}$ and a temperature of $20^{\circ} \mathrm{C}$ ) of $C$. maenas are presented in Table 3. Organism recovery ranged from $90 \%$ at site $\mathrm{S} 4$ to $100 \%$ at all remaining sites. A survival lower than $100 \%$ was only found at sites S2 and S3 (90\%), and also S4 (33.3\%). A one-way ANOVA revealed significant differences among postexposure feeding rates $\left(F_{(9,81)}=13.2, p<0.05\right)$. The Tukey HSD test revealed no differences among reference sites. Postexposure feeding rates were significantly depressed at all contaminated sites relatively to pooled references (R1 and R2a to R2d), by $16.3 \%$ to $72.7 \%$ (Table 3) (S1: $t_{58}=3.2, p<0.005$; S2: $t_{57}=4.39, p<0.001$; S3: $t_{57}=5.3, p<0.001 ; \quad \mathrm{S} 4: t_{51}=8.58, p<0.001 ; \quad \mathrm{S} 5$ : $\left.t_{58}=4.42, p<0.001\right)$.

\section{Discussion}

This study intended at developing a short-term sublethal in situ toxicity assay for estuarine sedimentoverlying waters with the crab C. maenas, based on postexposure feeding. For this, a method for quantifying C. maenas feeding rates was first developed under

Table 3

Mean $(n=10)$ of recovery $(\%)$, survival $(\%)$ and adjusted postexposure feeding rates (PEF, in pieces/min) of Carcinus maenas exposed in situ for $48 \mathrm{~h}$ at five reference (R1 and R2a to R2d) and five impacted sites (S1 to S5)

\begin{tabular}{lllll}
\hline Site & Recovery & Survival & PEF \pm SD $(\mathrm{CV})^{\mathrm{a}}$ & PEF depression $(\%)$ \\
\hline R1 & 100.0 & 100.0 & $0.99 \pm 0.14(14)$ & \\
R2a & 100.0 & 100.0 & $0.90 \pm 0.13(15)$ & \\
R2b & 100.0 & 100.0 & $0.85 \pm 0.11(14)$ & \\
R2c & 100.0 & 100.0 & $0.87 \pm 0.12(14)$ & \\
R2d & 100.0 & 100.0 & $0.98 \pm 0.09(9)$ & \\
S1 & 100.0 & 100.0 & $0.77 \pm 0.13(17)^{*}$ & 16.3 \\
S2 & 100.0 & 90.0 & $0.70 \pm 0.16(23)^{*}$ & 23.9 \\
S3 & 100.0 & 90.0 & $0.66 \pm 0.16(24)^{*}$ & 28.3 \\
S4 & 90.0 & 33.3 & $0.26 \pm 0.12(47)^{*}$ & 72.7 \\
S5 & 100.0 & 100.0 & $0.72 \pm 0.13(18)^{*}$ & 21.7
\end{tabular}

${ }^{\text {a }}$ Postexposure feeding rates adjusted to a salinity of $20 \mathrm{~g} / \mathrm{L}$ and a temperature of $20^{\circ} \mathrm{C}$.

* Significant $(p<0.005)$ postexposure feeding depression relative to pooled references. controlled conditions. Among the various types of tested foods, dried pieces of the Polychaeta $H$. diversicolor were demonstrated to be the most readily consumed food by $C$. maenas juveniles in a short period $(30 \mathrm{~min})$. The fact that the dried pieces did not disintegrate into the surrounding water after a 30-min period also allowed the accomplishment of consistent and precise feeding rates. Compared to the other types of tested food types, the dried pieces of the polychaetes presented a more prominent odor. Thus, the voracious predatory behavior of $C$. maenas in the presence of the dried polychaetes may be explained by the fact that decapod crustaceans are chemosensory and tactile predators, rather than visual ones (Cohen et al., 1995; Kaiser et al., 1993). Of significance is the fact that a short postexposure feeding period (only $30 \mathrm{~min}$ ) is essential for preventing an eventual physiological recovery from the effects of the toxicant during exposure (Brent and Herricks, 1998; McWilliam and Baird, 2002b).

Results from the feeding quantification experiments showed also that the feeding rate of $C$. maenas juveniles was not significantly dependent on gender. Differences in foraging behavior between individuals of different gender were reported and have been attributed to sexual dimorphism in chelae size (Elner, 1980). Yet, in agreement with our findings, Mascaró and Seed (2001) reported that for $C$. maenas individuals with less than $30 \mathrm{~mm}$ in carapace width, no sexual dimorphism in master chelae size is expected to occur among crabs, as chelae size in female and male crabs is similar. Despite the fact that in its natural environment $C$. maenas is in general more active during the night, including in feeding behavior (personal observation), no significant differences in feeding rate were observed in the present study between organisms fed under different light conditions. Yet, feeding under darkness was suggested to produce feeding rates with a higher reproducibility than feeding under continuous light. This result is in accordance with the findings from other authors for cladocerans (McWilliam and Baird, 2002a), chironomids (Soares et al., in press) and polychaetes (Moreira et al., in press). Thus, it was established that postexposure feeding rates should be quantified under dark 
conditions, since in this way more precise feeding rates are expected to be accomplished.

In the present study, the sensitivity of the postexposure feeding response in C. maenas was investigated by exposing organisms to sublethal and lethal concentrations of a reference toxicant (cadmium chloride). After a 48-h exposure to cadmium, postexposure feeding depression was more sensitive than lethality. The 48-h feeding $\mathrm{IC}_{50}$ was lower than the 48- and $96-\mathrm{h} \mathrm{LC}_{50}$ by 6.5 and 3.2 times, respectively. Several other studies have demonstrated that feeding depression on a variety of invertebrate species was a more sensitive endpoint than lethality in determining toxicity to a wide range of chemical compounds with different modes of action (Barata and Baird, 2000; McLoughlin et al., 2000; McWilliam and Baird, 2002b). For instance, feeding depression was found to be more sensitive than lethality in Daphnia magna, with an $\mathrm{IC}_{50}$ lower than the $\mathrm{LC}_{50}$ after one (approx. 3 days) and two (approx. 7 days) instars of exposure to cadmium, by 1.6 and 2.9 times, respectively (Barata and Baird, 2000). The latter authors also showed that the inhibition of feeding in D. magna was approximately 2.0 times more sensitive than lethality after one instar of exposure to fluoranthene. The inhibition of feeding in Gammarus pulex (L.) was also found to be approximately $62,35,30,19$, and 6 times more sensitive than lethality after $144-\mathrm{h}$ exposure to linear alkylbenzene sulfonate, zinc, pirimiphos-methyl, permethrin, and lindane, respectively (McLoughlin et al., 2000).

Although C. maenas is described as an extremely eurythermal and euryhaline hyper-osmoregulator, background variability in physiological and behavioral responses have been reported and associated with fluctuations in environmental conditions, such as water salinity and temperature (Bamber and Depledge, 1997). Considering this, the influence of several environmental exposure conditions (salinity, temperature, substrate, light, and food availability) on the postexposure feeding of $C$. maenas were studied here in separate experiments, under laboratory conditions. From all variables investigated, only the temperature and salinity conditions prevailing during a 48-h exposure period significantly influenced the postexposure feeding of $C$. maenas, and thus may act as confounding factors in an in situ assay. A nonlinear regression model showed that salinity explained $92.1 \%$ of the variability in postexposure feeding. Postexposure feeding after exposure at $5 \mathrm{~g} / \mathrm{L}$ salinity was considerably reduced compared to postexposure feeding after exposure at 20 and $35 \mathrm{~g} / \mathrm{L}$ salinities (by $48 \%$ and $51 \%$, respectively). Consequently, special attention should be taken when in situ deployments are to be performed at sites where low salinities are likely to occur, for example sites recently subject to heavy rainfall events provoking substantial declines in water column salinity. The nonlinear regression model explaining the relationship between postexposure feeding and temperature showed that $99.8 \%$ of the variability in postexposure feeding was ascribed to differences in exposure temperature. In accordance with our results, Wallace (1973) found that C. maenas acclimatized in the laboratory for 4 weeks at $24{ }^{\circ} \mathrm{C}$ ate 2.4 times more food than crabs acclimatized at $10{ }^{\circ} \mathrm{C}$. Elner (1980) found C. maenas shore crabs foraging rate, both in terms of food ingested and energy intake per day, to be higher at 17 than at $10{ }^{\circ} \mathrm{C}$. A significant effect of temperature on the feeding of G. pulex (Maltby et al., 2002) and on the postexposure feeding of $C$. riparius (Soares et al., in press) and $H$. diversicolor (Moreira et al., in press) has also been reported. The use of the proposed in situ assay in regions warmer than Portuguese estuaries should be carefully considered since the physiological performance of the crabs can be compromised, as revealed by the depression in feeding after exposure at $30{ }^{\circ} \mathrm{C}$, compared to exposure at $25{ }^{\circ} \mathrm{C}$.

In the present study, the establishment of models to explain C. maenas postexposure feeding in function of exposure salinity and temperature enabled adjusting the in situ postexposure feeding responses to the same water-column salinity and temperature values, and thus the direct comparison of postexposure feeding rates across sites. Strategies to distinguish a potential toxic effect from confounding factors associated with environmental parameters, as performed in the present study, have been successfully applied in other in situ assays (Maltby et al., 2002; Moreira dos Santos et al., 2002; Ringwood and Keppler, 2002). However, the application of such strategies should not exclude possible interactions between effects of environmental variables and those of contaminants (DeWitt et al., 1999; Maltby et al., 2002; Moreira dos Santos et al., 2002; Ringwood and Keppler, 2002).

To estimate a practicable maximum in situ exposure time, the influence of exposure time length on postexposure feeding was also assessed. Organisms were found to present similar postexposure feeding rates after subjected to a starvation period of 48,96 and $192 \mathrm{~h}$ (plus a $24-\mathrm{h}$ food deprivation prior to the assay). This finding suggests that in situ assays with $C$. maenas could be performed for periods longer than $48 \mathrm{~h}$, when using postexposure feeding as an endpoint. However, the selection of the exposure period for an in situ assay must be based on a compromise between sensitivity and costeffectiveness. Long-term in situ exposures are costly, both in terms of time and effort, and their practicability is also reduced by the increasing risks of vandalism. Since our data and results from other authors (Barata and Baird, 2000; Castro et al., 2004; McLoughlin et al., 2000; McWilliam and Baird, 2002a,b; Moreira et al., in press) show that feeding depression is a sensitive endpoint, capable of responding to toxicants in a short period of time, an in situ exposure period of $48 \mathrm{~h}$ seems 
to be suitable for assessing sediment-overlying water toxicity with $C$. maenas.

To evaluate the suitability of the proposed in situ assay for exposing $C$. maenas in the field and for in situ sediment-overlying-water toxicity evaluations, organisms were deployed at reference (5 sites) and contaminated estuaries (5 sites) along the Portuguese coast. Recovery rates were high, ranging from $90 \%$ at one site (S4) to $100 \%$ at all remaining sites, demonstrating the suitability of the in situ assay chambers and procedures to successfully deploy and retrieve C. maenas. As pointed out by other authors, the presence of local fauna inside in situ chambers may represent an important drawback for in situ sediment toxicity assessments (Castro et al., 2003). Our in situ assay design, employing a perforated cap and a mesh size of $200 \mu \mathrm{m}$ was found to be appropriate to prevent the entrance of local fauna and also of potential predators. Light penetration was also an important aspect taken into consideration in the assay chamber design. The employment of transparent material in assay chamber construction allows the deployment of organisms under a natural light regime and the integration of potential light and toxicant effects on organism performance (Castro et al., 2003; Ireland et al., 1996).

A significant postexposure feeding depression was detected at all contaminated estuaries, demonstrating that $C$. maenas postexposure feeding was a general and responsive sublethal endpoint. It should be mentioned that sites S3 and S4, where the postexposure feeding of C. maenas was most depressed $(28.3 \%$ and $72.7 \%$, respectively) were located at the estuaries considered most affected in terms of human influence (Ave and Douro) (Ferreira et al., 2003; Guerreiro and Pereira, 2002). Furthermore, the present results are in accordance with those of a previous in situ assay with the Polychaeta $H$. diversicolor performed at the same reference and contaminated estuaries (Moreira et al., in press). In the latter study, the two highest postexposure feeding depressions were also detected at the Ave and Douro estuaries. Semivolatile organic compounds of industrial origin (e.g. chlorophenols, tributylphosphate) and metals have been reported as contaminants of main concern in these estuaries (Azevedo et al., 2000; Gonçalves et al., 1994; Lacorte et al., 2001; Mucha et al., 2003). However, the interpretation of toxic responses from mixtures of contaminants is often very complex because possible interactions among contaminants can produce synergistic or antagonistic effects.

Increased emphasis has been placed on the development of methodologies that use behavioral responses of aquatic animals as indicators of contaminant exposure. Although all behavioral responses are potentially vulnerable to contaminant inputs, most work with crustaceans has been carried out on feeding behavior (Walker et al., 2001), especially with G. pulex
(Maltby et al., 2002 and references therein) and $D$. magna (McWilliam and Baird, 2002a,b). Several studies have demonstrated that a toxic impairment on feeding influences the organism physiological performance and has the potential to interfere with specific life-history events, such as growth, reproduction and eventually survival (Maltby et al., 2001). For instance, Maltby and Naylor (1990) addressed the effect of zinc on the energy budget of $G$. pulex and were able to associate a reduction in feeding rate with long-term reproductive impairment. Also in C. maenas, a reduction in resource acquisition, expressed by a depression in postexposure feeding rate, will very likely result in a decrease in the intake/ expenditure energy ratio, in detriment of growth and reproduction (Hebel et al., 1997). Ultimately, impairment in feeding can also have serious consequences on the community structure and functioning (Maltby and Naylor, 1990; Taylor et al., 1998).

\section{Conclusions}

From results shown in the present study, it can been seen that this novel in situ sublethal assay with C. maenas based on postexposure feeding may provide a rapid, reliable and responsive tool for detecting sediment-overlying water toxicity in estuaries. Therefore, and considering the lack of ecologically relevant assays for sediment toxicity evaluations in estuaries (Chapman and Wang, 2001), results obtained from in situ assays with $C$. maenas could provide essential sublethal data to be incorporated in estuarine ecological risk assessment studies.

\section{Acknowledgements}

This research was partially funded by Fundação para a Ciência e a Tecnologia (Portugal) (doctoral grant to the first author, reference SFRH/BD/5343/2001 and CONTROL project, reference PDCTM/MAR/15266/ 99). The authors thank D. Duarte for assistance during fieldwork.

\section{References}

Astley, K.N., Meigh, H.C., Glegg, G.A., Braven, J., Depledge, M.H., 1999. Multi-variate analysis of biomarker responses in Mytilus edulis and Carcinus maenas from the Tees estuary (UK). Marine Pollution Bulletin 39, 145-154.

ASTM (American Society for Testing and Materials), 2002. Standard guide for conducting acute toxicity tests on test materials with fishes, macroinvertebrates, and amphibians. E 729-96. In: Annual Book of American Society for Testing and Materials Standards, vol. 11.05. ASTM, Philadelphia, USA.

Azevedo, D.A., Lacorte, S., Vinhas, T., Viana, P., Barceló, D., 2000. Monitoring of priority pesticides and other organic pollutants in 
river water from Portugal by gas chromatography-mass spectrometry and liquid chromatography-atmospheric pressure chemical ionization mass spectrometry. Journal of Chromatography A 879, 13-26.

Bamber, S.D., Depledge, M.H., 1997. Evaluation of changes in the adaptive physiology of shore crabs (Carcinus maenas) as an indicator of pollution in estuarine environments. Marine Biology 129, 667-672.

Barata, C., Baird, D.J., 2000. Determining the ecotoxicological mode of action of chemicals from measurements made on individuals: results from instar-base tests with Daphnia magna Straus. Aquatic Toxicology 48, 195-209.

Brent, R.N., Herricks, E.E., 1998. Postexposure effects of brief cadmium, zinc, and phenol exposures on freshwater organisms. Environmental Toxicology and Chemistry 17, 2091-2099.

Buchanan, J.B., Kain, J.M., 1971. Measurement of the physical and chemical environment. In: Holme, N.A., McIntyre, A.D. (Eds.), Methods for the Study of Marine Benthos. Blackwell Scientific Publications, Oxford, UK, pp. 30-58.

Castro, B.B., Guilhermino, L., Ribeiro, R., 2003. In situ bioassay chambers and procedures for assessment of sediment toxicity with Chironomus riparius. Environmental Pollution 123, 325-335.

Castro, B.B., Sobral, O., Guilhermino, L., Ribeiro, R., 2004. An in situ bioassay integrating individual and biochemical responses using small fish species. Ecotoxicology 13, 667-681.

Chapman, P.M., Wang, F., 2001. Assessing sediment contamination in estuaries. Environmental Toxicology and Chemistry 20, 3-22.

Chappie, D.J., Burton Jr., G.A., 2000. Applications of aquatic and sediment toxicology testing in situ. Soil and Sediment Contamination 9, 219-245.

Cohen, A.N., Carlton, J.T., Fountain, M.C., 1995. Introduction, dispersal and potential impacts of the green crab Carcinus maenas in San Francisco Bay, California. Marine Biology 122, 225-237.

Commission of the European Communities, 1976. Dangerous substances discharged into the environment. L 129. In: Official Journal of the European Community, Directive 76/464/CEE. Brussels, Belgium.

DeWitt, T.H., Hickey, C.W., Morrisey, D.J., Nipper, M.G., Roper, D.S., Williamson, R.B., Van Dam, L., Williams, E.K., 1999. Do amphipods have the same concentration-response to contaminated sediment in situ as in vitro? Environmental Toxicology and Chemistry 18, 1026-1037.

Elner, R.W., 1980. The influence of temperature, sex and chela size in the foraging strategy of the shore crab, Carcinus maenas (L.). Marine Behaviour and Physiology 7, 15-24.

Ferreira, J.G., Simas, T., Nobre, A., Silva, M.C., Shifferegger, K., Lencart-Silva, J., 2003. Identification of Sensitive Areas and Vulnerable Zones in Transitional and Coastal Portuguese Systems Application of the United States National Estuarine Eutrophication Assessment to the Minho, Lima, Douro, Ria de Aveiro, Mondego, Tagus, Sado, Mira, Ria Formosa and Guadiana Systems. Instituto da Água and Institute of Marine Research, Lisboa, Portugal.

Gonçalves, E.P.R., Soares, H.M.V.M., Boaventura, R.A.R., Machado, A.A.S.C., Esteves da Silva, J.C.G., 1994. Seasonal variations of heavy metals in sediments and aquatic mosses from the Cávado river basin (Portugal). Science of the Total Environment $142,143-156$.

Guerreiro, N., Pereira, P.B., 2002. Poluição e Qualidade da Água. Instituto da Água, Lisboa, Portugal.

Guillard, R.R.L., 1983. Culture of phytoplankton for feeding marine invertebrates. In: Berg Jr., C.J. (Ed.), Culture of Marine Invertebrates. Hutchinson-Ross, Stroudsberg, PA, pp. 108-132.

Hebel, D.K., Jones, M.B., Depledge, M.H., 1997. Responses of crustaceans to contaminant exposure: a holistic approach. Estuarine. Coastal and Shelf Science 44, 177-184.

Ireland, D.S., Burton Jr., G.A., Hess, G.G., 1996. In situ evaluations of turbidity and photoinduction of polycyclic aromatic hydrocarbons. Environmental Toxicology and Chemistry $15,574-581$.

Kaiser, M.J., Hughes, R.N., Gibson, R.N., 1993. Factors affecting diet selection in the shore crab, Carcinus maenas (L.). Animal Behaviour 45, 83-92.

Lacorte, S., Viana, P., Guillamon, M., Tauler, R., Vinhas, T., Barceló, D., 2001. Main findings and conclusions of the implementation of Directive 76/464/CEE concerning the monitoring of organic pollutants in surface waters (Portugal, April 1999May 2000). Journal of Environmental Monitoring 3, 475-482.

Lytle, J.S., Lytle, T.F., 2001. Use of plants for toxicity assessment of estuarine ecosystems. Environmental Toxicology and Chemistry 20, 68-83.

Maltby, L., Naylor, C., 1990. Preliminary observations on the ecological relevance of the Gammarus 'scope for growth' assay: effect of zinc in reproduction. Functional Ecology 4, 393-397.

Maltby, L., Kedwards, T.J., Forbes, V.E., Grasman, K., Kammenga, J.E., Munns Jr., W.R., Ringwood, A.H., Weis, J.S., Wood, S.N., 2001. Linking individual-level responses and population-level consequences. In: Baird, D.J., Burton Jr., G.A. (Eds.), Ecological Variability: Separating Natural from Anthropogenic Causes of Ecosystem Impairment. Society of Environmental Toxicology and Chemistry Press, Pensacola, FL, pp. 27-82.

Maltby, L., Clayton, S.A., Wood, R.M., McLoughlin, N., 2002. Evaluation of the Gammarus pulex in situ feeding assay as a biomonitor of water quality: robustness, responsiveness, and relevance. Environmental Toxicology and Chemistry 21, 361-368.

Mascaró, M., Seed, R., 2001. Foraging behavior of juvenile Carcinus maenas (L.) and Cancer pagurus L. Marine Biology 139, 1135-1145.

McLoughlin, N., Yin, D., Maltby, L., Wood, R.M., Yu, H., 2000. Evaluation of sensitivity and specificity of two crustacean biochemical biomarkers. Environmental Toxicology and Chemistry 19, 2085-2092.

McWilliam, R.A., Baird, D.J., 2002a. Application of postexposure feeding depression bioassays with Daphnia magna for assessment of toxic effluents in rivers. Environmental Toxicology and Chemistry $21,1462-1468$.

McWilliam, R.A., Baird, D.J., 2002b. Postexposure feeding depression: a new toxicity endpoint for use in laboratory studies with Daphnia magna. Environmental Toxicology and Chemistry 21, 1198-1205.

Moreira, S.M., Moreira-Santos, M., Guilhermino, L., Ribeiro, R. A short-term sublethal in situ toxicity assay with Hediste diversicolor (Polychaeta) for estuarine sediments based on postexposure feeding. Environmental Toxicology and Chemistry 24 (8), in press.

Moreira dos Santos, M., Moreno-Garrido, I., Gonçalves, F., Soares, A.M.V.M., Ribeiro, R., 2002. An in situ bioassay for estuarine environments using the microalga Phaeodactylum tricornutum. Environmental Toxicology and Chemistry 21, 567-574.

Mucha, A.P., Vasconcelos, M.T.S.D., Bordalo, A.A., 2003. Macrobenthic community in the Douro estuary: relations with trace metals and natural sediment characteristics. Environmental Pollution 121, 169-180.

Raffaelli, D., Conacher, A., McLachlan, H., Ernes, C., 1989. The role of epibenthic crustacean predators in an estuarine food web. Estuarine, Coastal and Shelf Science 28, 149-160.

Reid, D.G., Abelló, P., Kaiser, M.J., Warman, C.G., 1997. Carapace colour, inter-moult duration and the behavioural and physiological ecology of the shore crab Carcinus maenas. Estuarine, Coastal and Shelf Science 44, 203-211.

Ringwood, A.H., Keppler, C.J., 2002. Comparative in situ and laboratory sediment bioassays with juvenile Mercenaria mercenaria. Environmental Toxicology and Chemistry 21, 1651-1657.

Sakuma, M., 1998. Probit analysis of preference data. Applied Entomology and Zoology 33, 339-347.

Smolders, R., Bervoets, L., De Coen, W., Blust, R., 2004. Cellular energy allocation in zebra mussels exposed along a pollution 
gradient: linking cellular effects to higher levels of biological organization. Environmental Pollution 129, 99-112.

Soares, H.M.V.M., Boaventura, R.A.R., Machado, A.A.S.C., Esteves da Silva, J.C.G., 1999. Sediments as monitors of heavy metal contamination in the Ave river basin (Portugal): multivariate analysis of data. Environmental Pollution 105, 311-323.

Soares, S., Cativa, I., Moreira-Santos, M., Soares, A.M.V.M., Ribeiro, R. A cost-effective sublethal in situ sediment assay with Chironomus riparius based on postexposure feeding. Archives of Environmental Contamination and Toxicology, in press.

Tauler, R., Lacorte, S., Guillamón, M., Céspedes, R., Viana, P., Barceló, D., 2004. Chemometric modelling of main contamination sources in surface waters of Portugal. Environmental Toxicology and Chemistry 23, 565-575.
Taylor, G., Baird, D.J., Soares, A.M.V.M., 1998. Surface binding of contaminants by algae: consequences for lethal toxicity and feeding to Daphnia magna Straus. Environmental Toxicology and Chemistry 17, 412-419.

Walker, C.H., Hopkin, S.P., Sibly, R.M., Peakall, D.B., 2001. Principles of Ecotoxicology. Taylor and Francis, London, UK, pp. 133-152.

Wallace, J.P., 1973. Feeding, starvation and metabolic rate in the shore crab Carcinus maenas. Marine Biology 20, 277-281.

Watson, G.M., Andersen, O.-K., Galloway, T.S., Depledge, M.H., 2004. Rapid assessment of polycyclic aromatic hydrocarbon (PAH) exposure in decapod crustaceans by fluorimetric analysis of urine and haemolymph. Aquatic Toxicology 67, 127-142.

Zar, J.H., 1996. Biostatistical Analysis. Prentice Hall, Upper Saddle River, NY, USA. 